\title{
A PRESENÇA DA IMIGRAÇÃO ITALIANA NAS PAISAGENS E CENÁRIOS PRODUTIVOS RURAIS NO MUNICÍPIO DE GUAPORÉ/RS
}

\author{
The presence of Italian immigration in landscapes and rural production scenarios in the \\ municipality of Guaporé/RS
}

\section{La presencia de la inmigración italiana en los paisajes y cenarios productivos rurales en el municipio de Guaporé/RS}

Mateus Pessetti ${ }^{1}$ http://orcid.org/0000-0001-5228-7435

Luciane Rodrigues de Bitencourt ${ }^{2}$ http://orcid.org/0000-0003-3948-4199

\footnotetext{
1 Acadêmico do curso de Geografia - Licenciatura da Universidade de Passo Fundo/UPF. Email: mateuspessetti@ hormail.com.

${ }^{2}$ Professora Dr ${ }^{\mathrm{a}}$ do curso de Geografia da Universidade de Passo Fundo/UPF. Email: 1rb@upf.br.
}

\section{Resumo}

O presente trabalho busca identificar a presença da imigração italiana nas paisagens rurais do município de Guaporé/RS. Especificamente, contextualiza-se o processo de ocupação da imigração italiana no Rio Grande do Sul, especialmente de Guaporé, as contribuições e a materialização da referida etnia nas paisagens rurais, com ênfase para os aspectos relacionados ao cenário produtivo. A pesquisa fundamenta-se na pesquisa bibliográfica dos temas centrais e na realização do trabalho de campo, onde faz-se a coleta de material fotográfico para a análise. Estabelecida a matriz teórico-conceitual juntamente com a coleta de material em campo, realizam-se as discussões. Desta forma, o colono italiano perpetua-se no cenário produtivo através do cultivo de milho e uva, para o consumo próprio e para o comércio local/regional/nacional.

Palavras-chave: Geografia Cultural. Geografia Agrária. Paisagem Cultural.

\begin{abstract}
The present work seeks to identify the presence of Italian immigration in the rural landscapes of the municipality of Guaporé / RS. Specifically, the process of occupation of Italian immigration in Rio Grande do Sul, especially Guapore, is contextualized, the contributions and the materialization of this ethnic group in the rural landscapes, with emphasis on the aspects related to the productive scenario. The research is based on the bibliographical research of the central themes and the accomplishment of the field work, where the photographic material is collected for the analysis. Established the theoretical-conceptual matrix together with the collection of material in the field, the discussions are held. In this way, the Italian colonist perpetuates itself in the productive scenario through the cultivation of corn and grapes, for own consumption and for local / regional / national trade.
\end{abstract}

Keywords: Cultural Geography. Agrarian Geography. Cultural Landscape.

\section{Resumen}

El presente trabajo busca identificar la presencia de la inmigración italiana en los paisajes rurales del municipio de Guaporé / RS. En concreto, se contextualiza el proceso de ocupación de la inmigración italiana en Rio Grande do Sul, especialmente de Guaporé, las contribuciones y la materialización de dicha etnia en los paisajes rurales, con énfasis en los aspectos relacionados al escenario productivo. La investigación se fundamenta en la investigación bibliográfica de los temas centrales y en la realización del trabajo de campo, 
donde se realiza la recolección de material fotográfico para el análisis. Establecida la matriz teóricoconceptual junto con la recolección de material en campo, se realizan las discusiones. De esta forma, el colono italiano se perpetúa en el escenario productivo a través del cultivo de maíz y uva, para el consumo propio y para el comercio local / regional / nacional.

Palabras-clave: Geografía Cultural. Geografía Agraria. Paisaje Cultural.

\section{Introdução}

O território do Estado do Rio Grande do Sul constitui-se por uma formação étnicacultural diversificada, resultante de um longo processo de ocupação. Tal processo, ocorreu em fases distintas de colonização e de povoamento, originando territorialidades que refletem-se nas múltiplas paisagens (BRUM NETO, 2012). Desta forma, o fator cultural tornou-se determinante nas formas da organização do território rio-grandense, bem como, no contraste paisagístico cultural que perpetua-se até os dias atuais.

A ocupação territorial do Rio Grande do Sul iniciou com a chegada dos açorianos em 1732, na região sul e litorânea. Posteriormente, chegaram alemães, franceses, italianos e espanhóis, que aos poucos foram ocupando a região central do Estado, bem como, toda metade norte, até então coberta pela Mata Atlântica. Dentre os povos étnicos citados, destacam-se os italianos, uma vez que, em números, foram a etnia mais significativa no Rio Grande do Sul, da mesma maneira, sendo responsáveis por grande parte da atual configuração territorial. Tal etnia foi responsável pelo desbravamento de praticamente toda a metade norte do Estado, concentrando-se nas áreas de relevo acidentado e com potencial para a agricultura

Portanto, estas características geográficas, permitiram o desenvolvimento da produção agrícola calcada no cultivo de milho, trigo e a uva. Em especial, a produção vitivinicultora veio como consequência da tradição e cultura italiana. Hoje, no Planalto Meridional, especialmente nas áreas serranas, a produção de uvas e vinho é destaque e movimenta a economia de inúmeros municípios oriundos da colonização italiana. Desta forma, a presença desses imigrantes, faz-se presente até os dias de hoje, e pode ser identificada através dos elementos culturais e rurais presentes nas paisagens.

Em vista disso, o presente estudo, tem como objetivo geral identificar a presença da imigração italiana nas paisagens do município de Guaporé/RS, com ênfase aos aspectos relacionados ao espaço rural. Como objetivos específicos, busca-se: a) contextualizar o 
processo de inserção da imigração italiana em Guaporé/RS; b) compreender a contribuição da etnia italiana na organização do espaço rural; e, c) investigar a materialização da cultura italiana nas paisagens rurais. Assim, a pesquisa organiza-se através das etapas: a) fundamentação teórica a respeito dos conceitos centrais da pesquisa; b) contextualização do processo de ocupação do território gaúcho, com ênfase na etnia italiana, através de levantamento de dados secundários e de pesquisa bibliográfica; c) realização do trabalho de campo para obtenção de fotografias das paisagens rurais do município de Guaporé, que caracterizam e ressaltam a presença da etnia italiana, possibilitando a interpretação das paisagens; e, d) análise dos resultados, perante o material fotográfico obtido através da prática de campo.

\section{$O$ conceito de paisagem na ciência geográfica}

A Geografia, enquanto ciência, é estruturada por conceitos fundamentais para o desenvolvimento da pesquisa socioespacial. Dentre os pilares da referida ciência, destaca-se o conceito de paisagem. O mesmo surge com a institucionalização científica-metodológica da Geografia, perdurando ao longo das transformações paradigmáticas desta, sendo discutida sob a ótica de diferentes correntes do pensamento, ou seja, a compreensão da paisagem acompanhou as metamorfoses estabelecidas pelas diversas escolas do conhecimento geográfico, desde a influência positivista até a dialética marxista.

Deste modo, na chamada Geografia Clássica no Século XIX, a paisagem era estudada sob a ótica descritiva, ou seja, calcada na observação dos fenômenos, dando ênfase para as questões naturalistas. Conforme Cristofolleti (1999), essa abordagem descritiva mostra que, em sua função estético-descritiva, a palavra paisagem teve seu desenvolvimento inicial relacionado com o paisagismo e com a arte dos jardins. Dentre os autores que contribuíram para os estudos da paisagem, destacam-se Alexander Von Humboldt (1769-1859) e Richthofen (1833-1905).

Na virada e início do século XX, com a institucionalização da Geografia TeoréticaQuantitativa, novas visões sobre o referido conceito foram surgindo. Salienta-se que no paradigma em questão, a filosofia norteadora era o positivismo-lógico, e, portanto, os estudos paisagísticos eram de cunho mais técnico, priorizando as questões físicas com relação aos aspectos socioeconômicos, entendendo-se que ambos os elementos mantinham-se integrados, e assim, poderiam ser compreendidos como um sistema. Durante este período o conceito de paisagem sofreu grande influência da Teoria Geral dos Sistemas. 
Segundo Becker

A análise de sistemas em Geografia utiliza o princípio da conectividade, entendido como a correlação e a conectividade entre as variáveis, alcançada por meio da abordagem sistêmica. Na abordagem sistêmica, os fenômenos são analisados e considerados como resultado de uma relação entre diversos elementos e atributos. (BECKER, 2006, p. 84)

Com o surgimento da Geografia Crítica em meados dos anos 70 do século XX, renovam-se as discussões do corpo científico da Geografia. Conforme Becker (2006, p. 87) “(...) a Geografia Nova, propõe novas metodologias e filosofias alternativas em relação ao positivismo, dando uma orientação de caráter mais antropocêntrico na visão filosófica do marxismo de Marx e Engels". Desta forma, o conceito de paisagem ganhou um significado mais crítico, ligado a produção de diferentes espaços. De acordo com Cavalcanti

(...) a paisagem é o ponto de partida para a aproximação de seu objeto de estudo que é o espaço geográfico, contendo ao mesmo tempo uma dimensão objetiva e subjetiva. A paisagem é expressa na forma do espaço ou sua manifestação visível, concebida e percebida, onde a identificação das regiões deve se basear no que é essencial no processo de produção do espaço ou a divisão sócio-espacial. (CAVALCANTI, 2011, p. 69)

Na atual Geografia Humanística, calcada na subjetividade, nas relações com os lugares e no espaço vivido, a paisagem, segundo Cavalcanti (2011, p. 71) “(...) é definida como um organismo social considerado como um espaço subjetivo, sentido e vivido por cada ser humano, um espaço individualizado." Desta forma, reitera-se as relações culturais e sociais dos indivíduos e suas implicações no desenho de múltiplas paisagens.

\section{Cultura e Paisagem}

A Geografia tem como um de seus objetivos compreender a relação estabelecida entre o homem/sociedade e natureza. Tal relação perpetua-se nas diferentes formas de organização do espaço, que consequentemente, produzem uma multiplicidade paisagística. Na ciência geográfica, por meio do estudo cultural, pode-se identificar semelhanças entre os indivíduos de uma determinada comunidade, bem como, as particularidades na organização espacial da mesma. Tais semelhanças e particularidades evidenciam nas paisagens os traços culturais que os distinguem dos demais grupos sociais.

Segundo Wagner e Mikessel, o estudo cultural 
(...) oferece um meio para classificar os seres humanos em grupos bem definidos, de acordo com características comuns verificáveis, e também um meio para classificar áreas de acordo com as características dos grupos humanos que as ocupam. (WAGNER; MIKESSEL, 2014, p. 28)

Deste modo, salienta-se que o fator cultural atua como intermediário na produção de disparidades espaciais, bem como, sendo um dos atores que deixa cravado no espaço as manifestações culturais de um povo. Claval (1999, p. 61), aponta que a cultura “(...) é uma criação coletiva e renovada dos homens. Ela modela os indivíduos e define o contexto da vida social que são ao mesmo tempo os meios de organizar e de dominar o espaço"

À medida que o homem ganha o espaço e o define como morada, seus traços culturais são deixados, e assim, um espaço dotado de significações passa a ser constituído. Essas significações são explicitadas através de uma simbologia. De acordo com Cosgrove (2003 apud CORRÊA, 2009, p. 103), “(...) toda atividade humana é, ao mesmo tempo, material e simbólica, produção e comunicação". Portanto, à proporção que os grupos sociais tomam conta de seus espaços e os dotam de significados e simbologias, infere-se que, o cenário paisagístico também altera-se.

Reitera-se então que, é a partir da inserção do ser humano (cultura) no espaço que as paisagens naturais transformam-se e, portanto, passam a ser nomeadas de paisagens culturais. Muitas paisagens diferenciadas constituem-se partindo da existência de culturas, ou seja, da presença humana com seus costumes, símbolos e manifestações. Assim, a paisagem ganha significado cultural, ou seja, passa de um estado com elementos predominantemente naturais, para outro geografizado, podendo assim ser chamada de paisagem cultural. (CAETANO; BEZZI, 2011).

De acordo com Wagner e Mikessel entende-se por paisagem cultural

(...) um produto concreto e caraterístico da interação complicada entre uma determinada comunidade humana, abrangendo certas preferências e potenciais culturais, e um conjunto particular de circunstâncias naturais. É uma herança de um longo período de evolução natural e de muitas gerações de esforço humano. (WAGNER; MIKESSEL, 2014, p. 36)

Portanto, para compreender a paisagem cultural é necessário que o seu estudo vá além do materializado, ou seja, que busque-se detalhadamente entender os passos contrários, bem como, a interligação de todos os elementos que fazem dela sinônimo de cultura. Sendo a paisagem cultural um fragmento do espaço geográfico, pode-se dizer que a mesma, é a 
concretização de um processo sócio-histórico e que, portanto, a compressão apenas do que é visível e atual torna-se insuficiente. Posto isso, o seu reconhecimento deve ir além do visual, revelando o subjetivo, buscando a compreensão dos sons, cheiros e da sua alma. (FURNALETTO; KOZEL, 2014).

As manifestações paisagísticas culturais dão-se, em diversos fragmentos espaciais, dentre eles, o espaço rural. As simbologias culturais ligadas ao espaço rural relacionam-se com a produção agrícola, festas, estrutura fundiária, arquitetura, entre outros. É importante considerarmos que a cultura, no que tange o espaço rural e suas paisagens, serve como meio de resistência/permanência a inserção das tecnologias e da modernização do campo, que muitas vezes desconsidera e expulsa o processo de produção da cultura da área.

Nesse sentido, concordamos com Cruz, Araújo e Costa, quando diz que

Apesar das transformações que o ambiente rural está passando, a cultura tem a capacidade de se permanecer resistente, pois são passadas aos descendentes como uma memória coletiva, de resgate de vivências e lembranças. É interessante ressaltar que a cultura é um elemento social, impossível de se desenvolver individualmente. (CRUZ, ARAÚJO E COSTA 2015, p. 102)

Sendo assim, as paisagens do espaço rural são abrigos para uma vasta manifestação de culturas. No caso desta investigação, serão enfatizadas as características arquitetônicas, assim como, o cenário produtivo agrícola.

\section{A imigração italiana no Rio Grande do Sul e no município de Guaporé}

A chegada dos imigrantes italianos no Brasil, em especial ao Rio Grande do Sul, resultou em uma transformação do espaço geográfico e, consequentemente, na produção da multiplicidade paisagística presente até os dias de hoje. É importante considerarmos que o processo de ocupação territorial rio-grandense foi resultado de uma política imperial de incentivo a imigração. Tal política visava a exploração de áreas que ainda não haviam sido utilizadas, uma vez que a população da então província de São Pedro, concentrava-se praticamente na metade sul do Estado.

Desta forma, além do incentivo a imigração e a ocupação das terras, um dos propósitos das políticas imigratórias na região sul do Brasil, segundo Copatti (2010, p. 24) era de que "a ocupação dos espaços vazios no Sul também impediria o ataque de outros povos". Segundo Santos (1988, p.15) "a segunda metade do século XIX marca o começo das migrações 
maciças dos países "velhos" para as nações "novas" onde se instalaram centenas de milhares de europeus".

Até o momento da imigração italiana, no último quartel do século XIX, pode-se dizer que havia uma dualidade no Rio Grande do Sul, composta pelas charqueadas ao Sul e Oeste, e pelos imigrantes alemães que fixaram-se na depressão central, ocupando os vales do Rio dos Sinos, Caí, Taquari e Pardo. (BRUM NETO, 2012).

Quanto a política imperial, Bernardes destaca que:

Procurando acelerar a expansão da pequena propriedade de trabalho livre, o governo imperial criou, dentro de um grande plano, uma série de colônias no sul do país, destinadas a serem povoadas por italianos. No Rio Grande do Sul, as colônias deste plano foram Caxias, Conde D'Eu e Dona Isabel (187475), que deveriam constituir uma continuação da área já ocupada por alemães ao norte de Porto Alegre. (...) Os peninsulares, deste modo, conquistaram a região das araucárias em um ritmo muito mais acelerado do que os alemães. (BERNARDES, 1997, p. 75-76)

Sendo assim, a imigração italiana teve papel fundamental no desbravamento nas áreas de mata. Iniciou-se a ocupação no rebordo do planalto e posteriormente nos campos de cima da serra. Nessa perspectiva, sobre a imigração italiana, Curtis (1963 p. 32) salienta:

Na década de 1870, fixam-se serra acima, nas selvas dos afluentes do curso superior do Taquarí, entre os 600 e 800 metros, as colônias de Caxias (a pérola das colônias italianas). Garibaldi e Bento Gonçalves, já chamadas, com acerto, o cerne das colônias ítalo rio-grandenses. Avolumou-se, rapidamente, a imigração italiana, propiciando a formação de novos núcleos nesta zona pioneira: Alfredo Chaves (Veranópolis), 1884; Antônio Prado, 1886; Guaporé, 1892, constituindo-se no planalto oriental, à semelhança do que ocorrerá na encosta da serra com os alemães, uma zona característica de colonização italiana. (CURTIS, 1963, p. 32)

Desse modo, ressalta-se que, a partir da ocupação da metade norte do Rio Grande do Sul, em especial na região serrana, uma nova configuração espacial era dada ao território gaúcho. Até a segunda metade do Século XIX, a referida área era marcada pela presença da mata fechada, contrastando com a grande propriedade e as charqueadas ao sul do Estado. (Mapa1).

Em termos espaciais, a grande maioria dos municípios que surgiram decorrentes da referida imigração, possuíam um território inferior aos demais já constituídos no Estado. Naquele período, particularmente no final do Século XIX e início do Século XX, a grande quantidade de distritos e comunidades pertencentes aos seus municípios-mães foi desmembrando-se e criando novas unidades municipais. 
Mapa 1- localização dos territórios da Imigração Italiana no Rio Grande do Sul

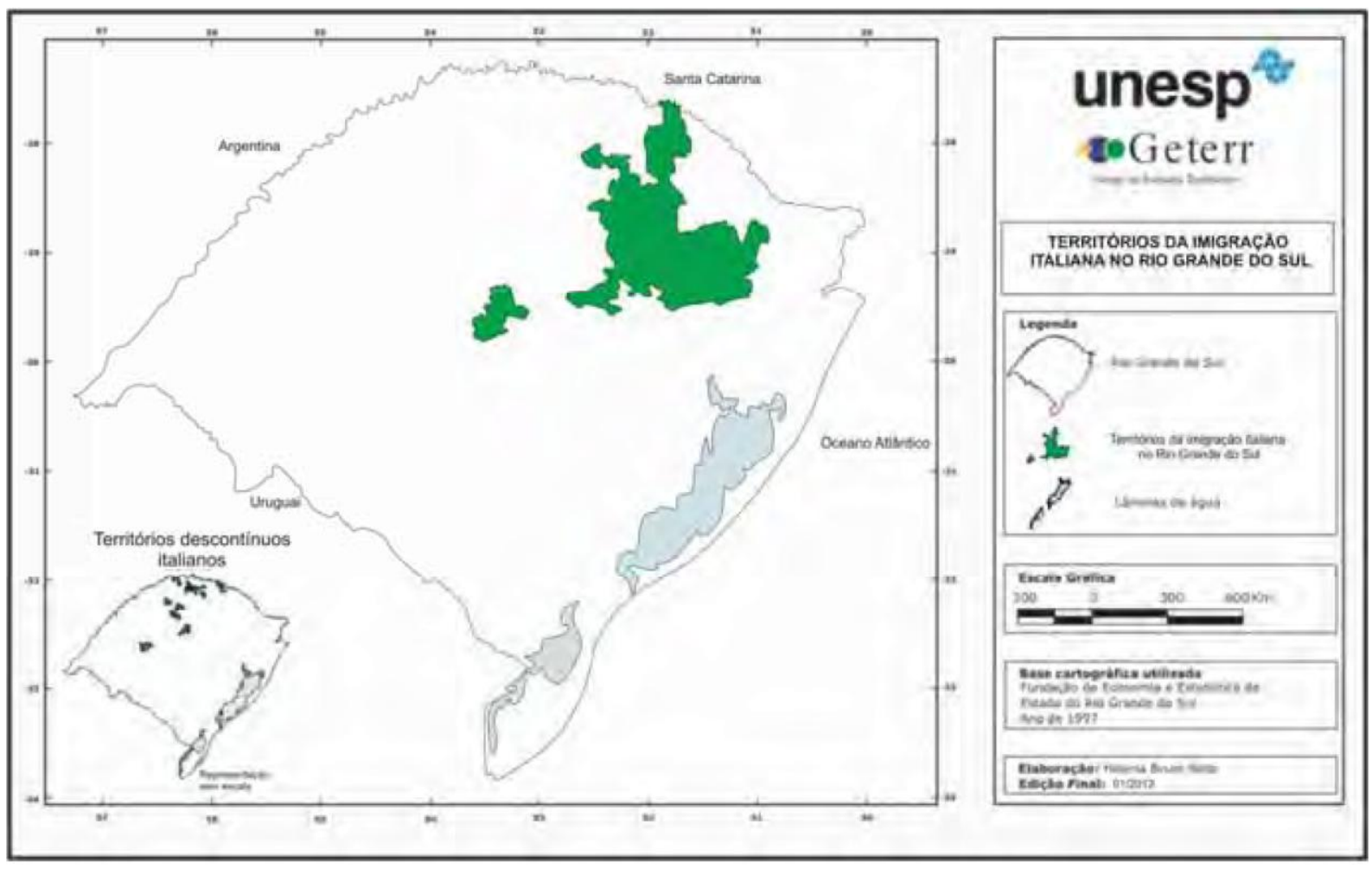

Fonte: Helena Brum Neto (2012)

Em vista disso, pode-se inferir que os imigrantes italianos foram os grandes responsáveis pela (re) configuração territorial do Rio Grande do Sul. A diversidade de costumes trazidos por eles deu origem a uma heterogeneidade de formas na organização espacial no Estado. Como aspectos relevantes, destaca-se a arquitetura, que materializou as preferências na organização de suas moradas, bem como, a produção agrícola, alicerçada na produção de milho, trigo e uva. (BRUM NETO, 2012).

A chegada da etnia ítalo no Estado foi de início, bastante dificultosa. As áreas que haviam sido destinadas para a colonização, conforme já mencionado, eram ocupadas por matas. Sendo assim, além das dificuldades nas instalações, os imigrantes italianos tinha como tarefa a abertura da mata, a retirada da madeira e do material basáltico oriundo do Planalto. A madeira e o basalto obtidos serviram de matéria-prima para construção de suas casas e para a delimitação das áreas.

Dentre os municípios fundados por imigrantes italianos, destaca-se Guaporé, o qual é a unidade de investigação deste trabalho. A colônia foi criada em 1892, sendo resultado do desmembramento de parte dos territórios de Lajeado e Passo Fundo. Logo, imigrantes das colônias de Bento Gonçalves, Caxias do Sul e Veranópolis chegaram ao local. Destarte, em 1896 a colônia já contava com 7 mil habitantes, na sua maioria italianos. Em 1910 já eram 30 
mil habitantes espalhados por todos os distritos do município. (PREFEITURA MUNICIPAL DE GUAPORÉ, 2017).

\section{O contexto geográfico do município de Guaporé/RS}

Localizado na metade norte do Rio Grande do Sul, na Microrregião Geográfica que leva o seu nome, o município de Guaporé (FIGURA 2) tem como limite a norte, Serafina Corrêa, a noroeste, União da Serra, a oeste, Arvorezinha, a sudoeste, Anta Gorda, ao sul, Dois Lajeados, a sudoeste, Fagundes Varela, a leste, Vista Alegre do Prata, e a nordeste, Nova Bassano. O referido município, possui um território de $298 \mathrm{~km}^{2}$ e uma população de 22.814 habitantes (IBGE, 2010), sua densidade demográfica é de 76,64 hab/km².

Mapa 2 - Localização do município de Guaporé/RS

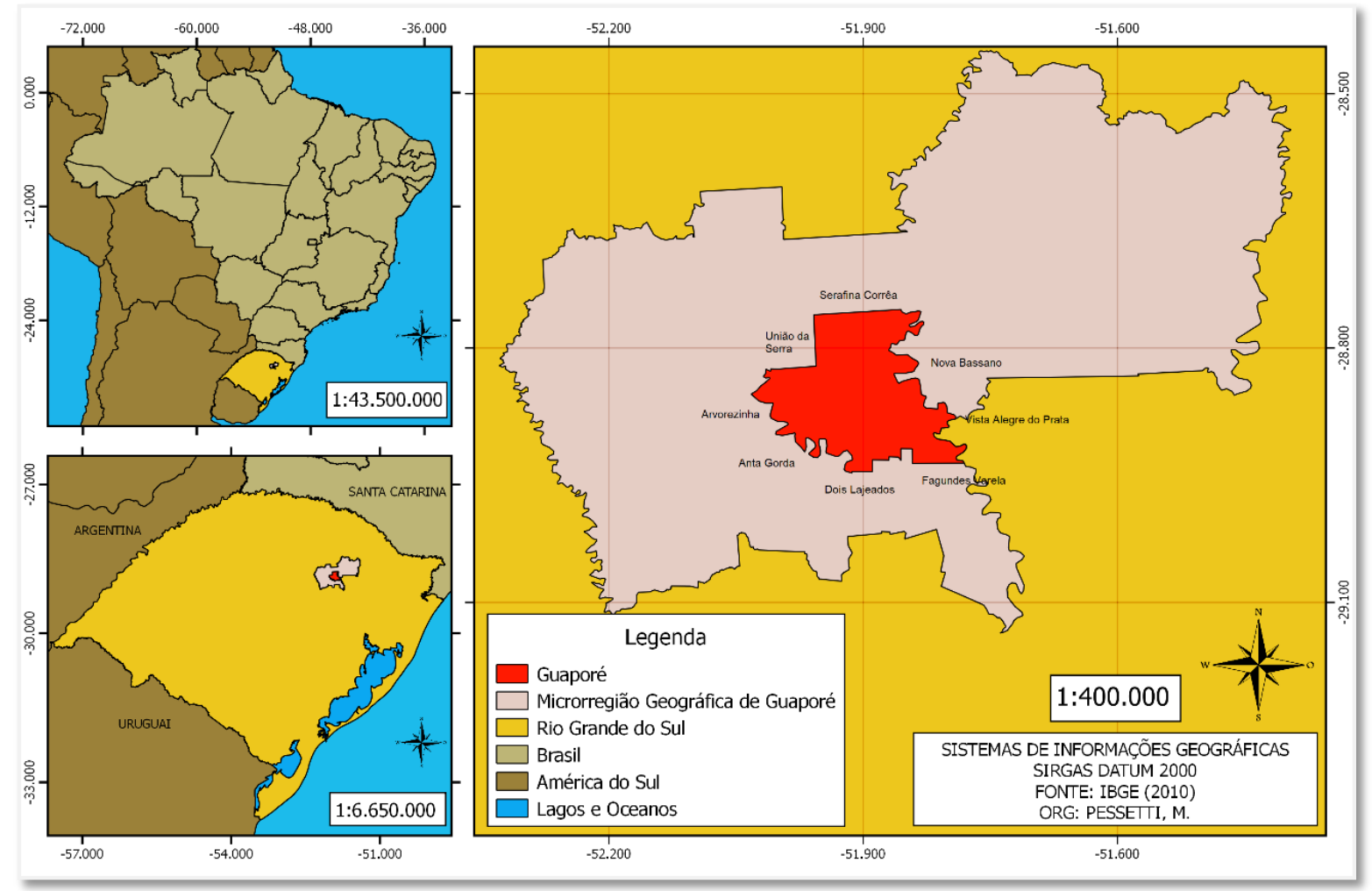

Fonte: IBGE (2010), adaptado por Mateus Pesseti (2018)

Em meio a Mata Atlântica, o município apresenta altitudes que variam de 450 metros nas áreas centrais, até 700 metros nos pontos mais elevados. Seu território está totalmente sobre o Planalto, apresentando formação rochosa basáltica. (SECRETARIA DE PLANEJAMENTO, GOVERNAÇA E GESTÃO, 2017).

Seu clima é caracterizado por apresentar temperaturas médias anuais de $16^{\circ}$ à $18^{\circ}$ graus, tendo chuvas bem distribuídas ao longo do ano. Os índices pluviométricos variam de 
1700 até 1900 milímetros anuais. Tais características climáticas são favoráveis para a produção agrícola, que tem como base o cultivo de milho, soja e uva. (SECRETARIA DE PLANEJAMENTO, GOVERNAÇA E GESTÃO, 2017).

Pontua-se que, anterior ao desenvolvimento da economia da indústria joalheira e de lingerie, o setor primário teve papel fundamental do desenvolvimento territorial, econômico e social de Guaporé. Seus principais produtos agrícolas eram arroz, feijão, milho, soja, laranja e uva. Contava ainda com 82 casas de negócios e algumas indústrias, destacando-se na produção de aguardente, banha, vinho, ovos e queijo. (PREFEITURA MUNICIPAL DE GUAPORÉ, 2017).

\section{As paisagens rurais de Guaporé/RS}

Os estudos sobre a diversidade paisagística e cultural no Rio Grande do Sul permitemnos compreender de maneira particular, as contribuições de cada etnia para tal configuração. Sendo assim, com a chegada dos imigrantes italianos no final do século XIX, desenvolveramse inúmeras atividades, com destaque para a atividade agrícola, que imprimia no território distintas configurações paisagísticas. Nesse sentido, a referida etnia trouxe em sua bagagem os conhecimentos com o manejo da terra, uma vez que em seus municípios de origem a atividade que mais se desenvolvia era a agricultura.

Além da sua contribuição no cenário produtivo agrícola, os italianos tiveram papel fundamental na organização espacial dos municípios que foram se originando em função da sua chegada. Desta forma, na unidade territorial investigada, a presença da imigração ítala também pode ser vista nos aspectos arquitetônicos. Em vista disso, nas áreas rurais de Guaporé, é muito comum encontrar grandes casarões produzidos com a madeira retirada da Mata Atlântica, acompanhados de porões feitos de pedra basáltica.

\section{Paisagens e cenário produtivo em Guaporé/RS}

Conforme dados secundários obtidos no Instituto Brasileiro de Geografia e Estatística - IBGE (2001, 2004, 2008, 2012 e 2016), a produção agrícola de Guaporé é bastante diversificada. Nas propriedades de pequeno e médio porte, são produzidas em maior número as culturas da erva-mate, milho, uva e soja. Como características da imigração italiana podemos apontar a cultura do milho e da uva. 
Foto 1- Paisagem do cultivo do milho em Vila Linha $7^{\text {a }}$ em Guaporé/RS

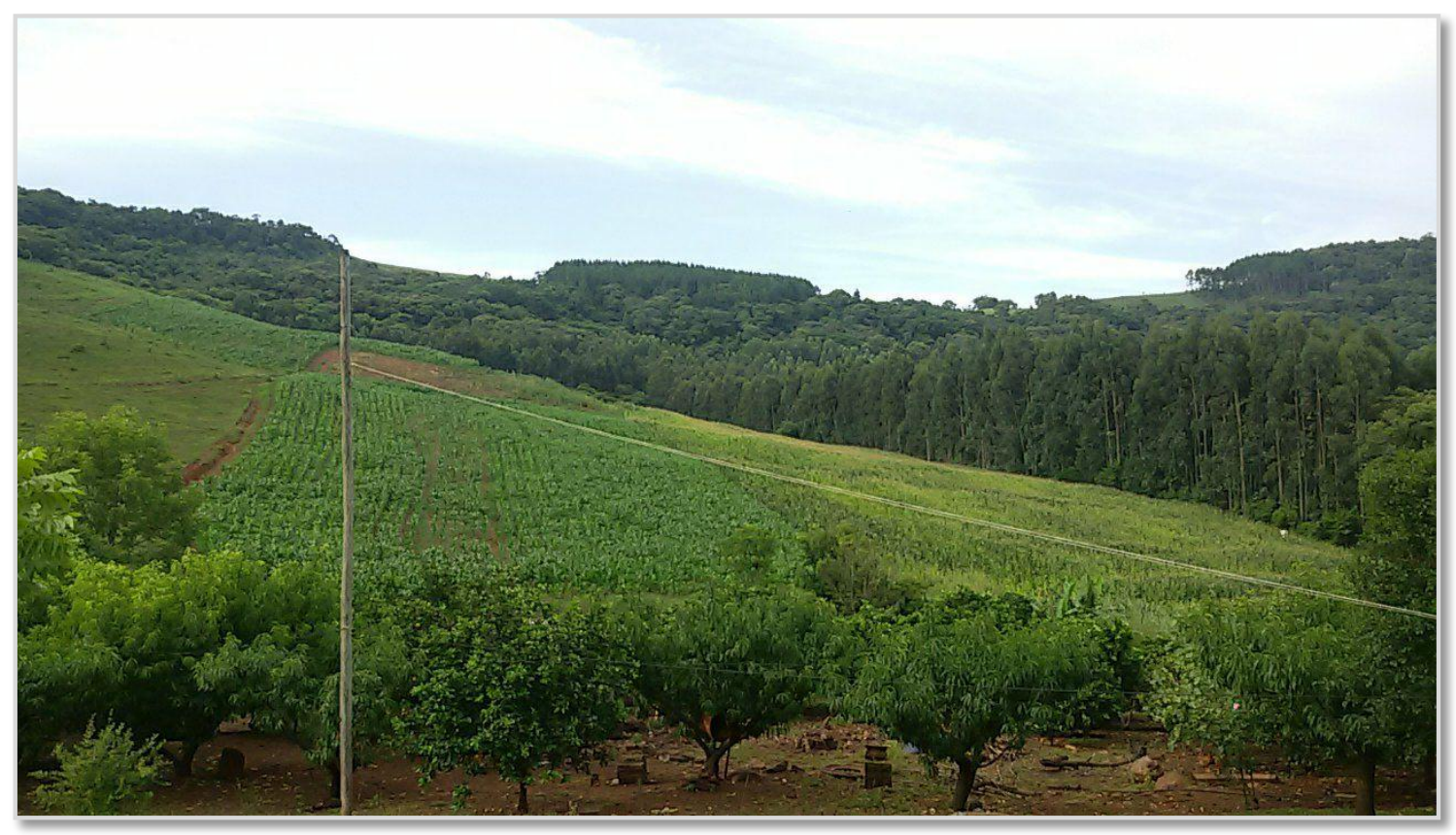

Fonte: Trabalho de campo, (Janeiro, 2017) Fotografia Mateus Pessetti

É importante salientarmos que o primeiro grão de milho não foi trazido pelos Italianos, uma vez que o mesmo é nativo da América, porém o desenvolvimento maior da produção na metade norte do Rio Grande do Sul foi resultado da sua inserção no espaço. Assim, no caso de Guaporé, de acordo com os dados coletados (gráfico 1), a referida cultura perpetua-se como a maior produção agrícola, ficando atrás da soja apenas nos dados de 2016. Em vista disso, conforme podemos observar na Figura 3, a materialização dessa etnia encontra-se perpetuada nas paisagens rurais do referido município, como pode ser observado na realização do trabalho de campo, bem como, em toda a área rural do recorte espacial analisado.

Gráfico 1- Produção de milho e soja no município de Guaporé/RS

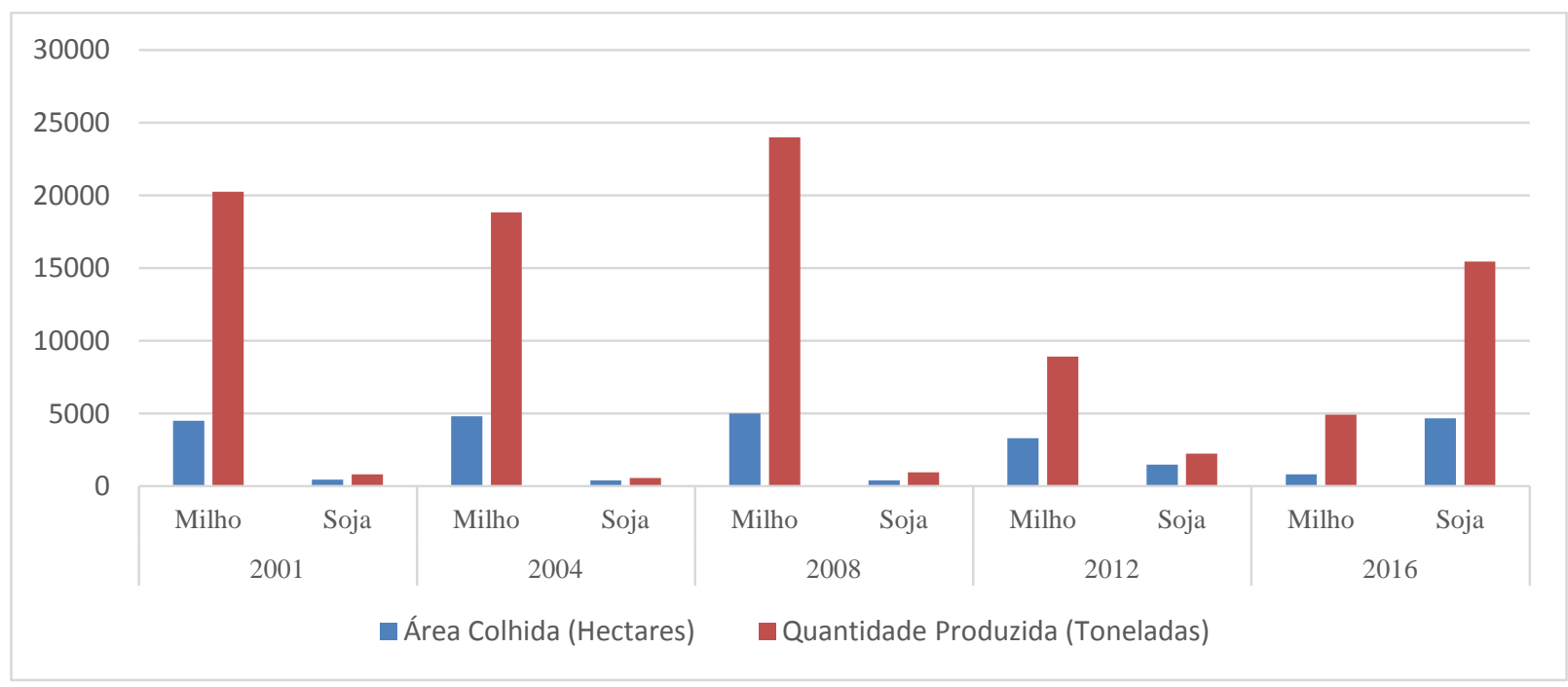

Fonte: SIDRA - IBGE (2017) 
De acordo com Trombini, Larote e da Rosa (2017, p. 12) "A grande maioria dos imigrantes italianos eram oriundos de regiões montanhosas da Itália e trouxeram consigo técnicas e práticas agrícolas. Na Itália praticavam a agricultura para o consumo alimentar". Desta forma, ao instalarem-se nas propriedades que possuíam características geográficas semelhantes às de seus locais de origem, de acordo com o gráfico 1 , o milho passou a ser cultivado, sendo utilizado para diversas finalidades, dentre elas a produção de farinha, aproveitada para o preparo da polenta e de bolos, bem como, servindo como alimentação de animais, especialmente os suínos. Aliava-se uma agricultura de subsistência com a mão de obra familiar.

Boni e Costa apud Larote e da Rosa salienta que

Inicialmente a colônia do imigrante italiano voltava-se para o suprimento das necessidades caseiras, num sistema de policultura. O colono tinha como interesse plantar os gêneros necessários para sua família e só depois colocar os excedentes para o mercado regional ou mesmo nacional (BONI e COSTA 1982 apud LAROTE; DA ROSA, 2017, P. 12)

Desta forma, o cultivo do milho foi um dos pilares iniciais para o desenvolvimento local/regional das áreas em que os imigrantes italianos se instalaram. Na unidade municipal investigada nesta pesquisa, o cultivo de milho perpetua-se como uma das principais culturas agrícolas, sendo produzido desde a origem da referida municipalidade.

Gráfico 2 - Produção de uva e erva-mate no município de Guaporé/RS

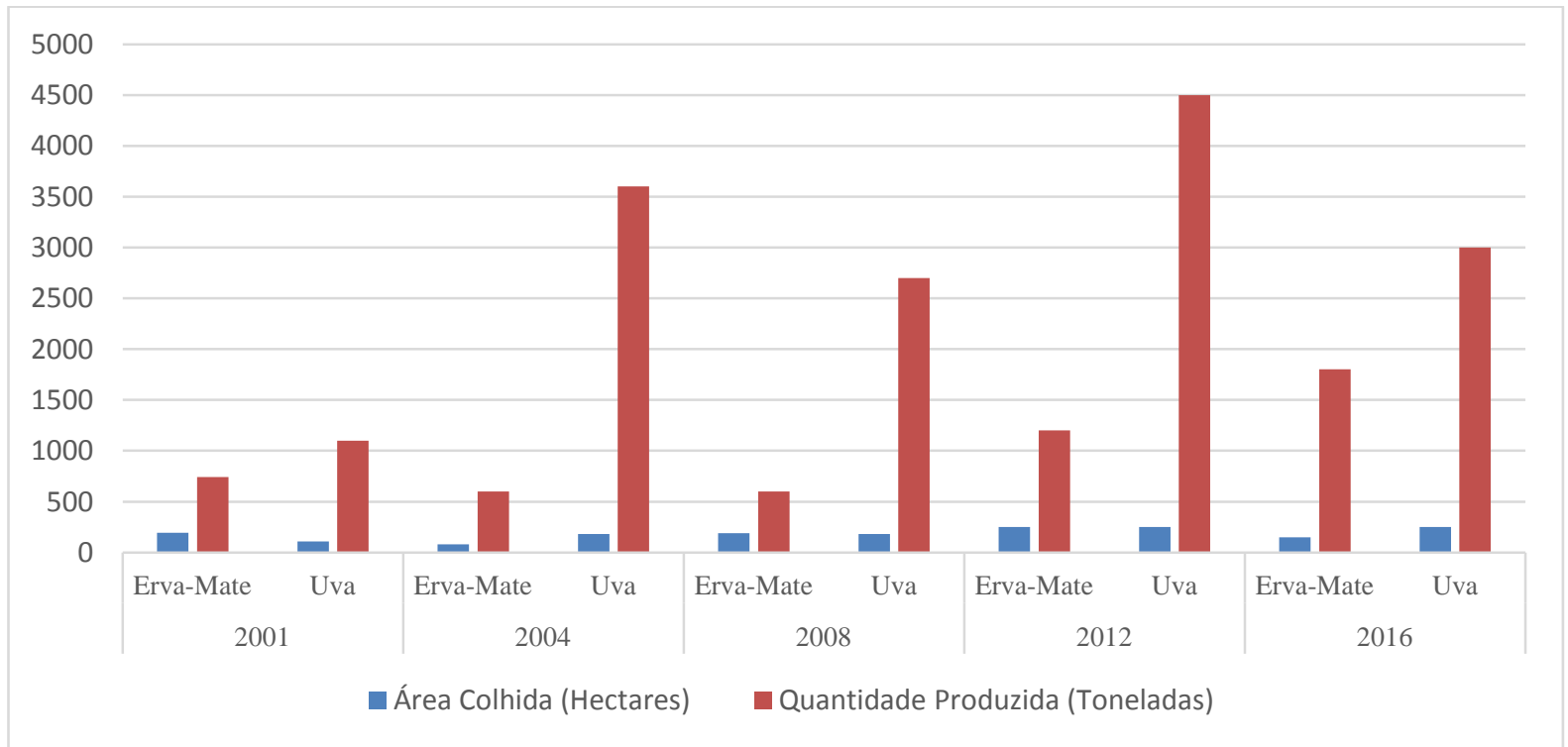

Fonte: SIDRA - IBGE (2017)

Nesse sentido, além do milho, a presença da etnia italiana faz-se materializada na produção vitivinicultora do município de Guaporé. No que se refere as lavouras permanentes, de acordo com os dados secundários do $\operatorname{IBGE}(2001,2004,2008,2012$ e 2016), o cultivo da 
uva é a segunda maior produção em área colhida e maior produção em quantidade produzida na unidade em investigação. (gráfico 2)

Desta forma, a produção vitivinicultora tornou-se a grande marca da presença de imigrantes italianos no Rio Grande do Sul, especialmente na Serra Gaúcha, em municípios como Caxias do Sul e Bento Gonçalves (BRUM NETO, 2017). Uma vez que grande parte da população que formou Guaporé era oriunda da colônia de Bento Gonçalves, o cultivo da uva na municipalidade mencionada seria apenas uma consequência.

Salienta-se que a primeira videira não foi inserida no Brasil pelos italianos, e sim pelos portugueses em 1535 na Capitania de São Vicente, porém sua produção só ganhou destaque com a chegada das famílias italianas (FALCATE, 2014). Portanto, a uva já era cultiva por jesuítas e alemães quando a imigração italiana ocupou o espaço do Rio Grande do Sul.

Vale ressaltar, segundo Brum Neto

A tradição do cultivo de uva pelos italianos e seus descendentes encontra alguns argumentos que procuram explicá-la nos seus territórios de origem. Como esses imigrantes eram provenientes de Vêneto, Friuli, Lombardia e Trento, em sua maioria, já tinham conhecimentos em relação à produção de uva e à vitivinicultura, pois essas regiões eram reconhecidas como tradicionais áreas de produção vinícola da Itália. (BRUM NETO, 2017, p. 17)

Deste modo, além da tradição da produção de vinhos, os italianos trouxeram nas suas bagagens conhecimentos técnicos que vieram a contribuir para o aperfeiçoamento do cultivo. Assim, a vitivinicultura passou a ganhar destaque, tornando-se fonte de renda e de desenvolvimento de famílias, bem como, de municípios e dos contextos regionais em que estavam inseridos.

No caso de Guaporé, a vitivinicultura é produzida em maior escala nas vinícolas, contudo, infere-se que, também, é bastante significativa a produção caseira dos vinhos nas propriedades de pequeno porte, com destino ao consumo próprio, assim como, o comércio em feiras. Durante a realização do trabalho de campo, foram visitados dois estabelecimentos produtores, uma vez que a quantidade de vinhas nas suas propriedades é a maior concentração do município.

Nesse sentido, nos estabelecimentos visitados, são produzidas as uvas: Francesa, Isabel, Cabernet e Merlot. Todo o cultivo dos referidos locais é voltado para a produção de vinhos, sucos e espumantes. Tais produtos são comercializados a nível local/regional/nacional.

Mosaico 1- Paisagens da vitivinicultura em Guaporé/RS 


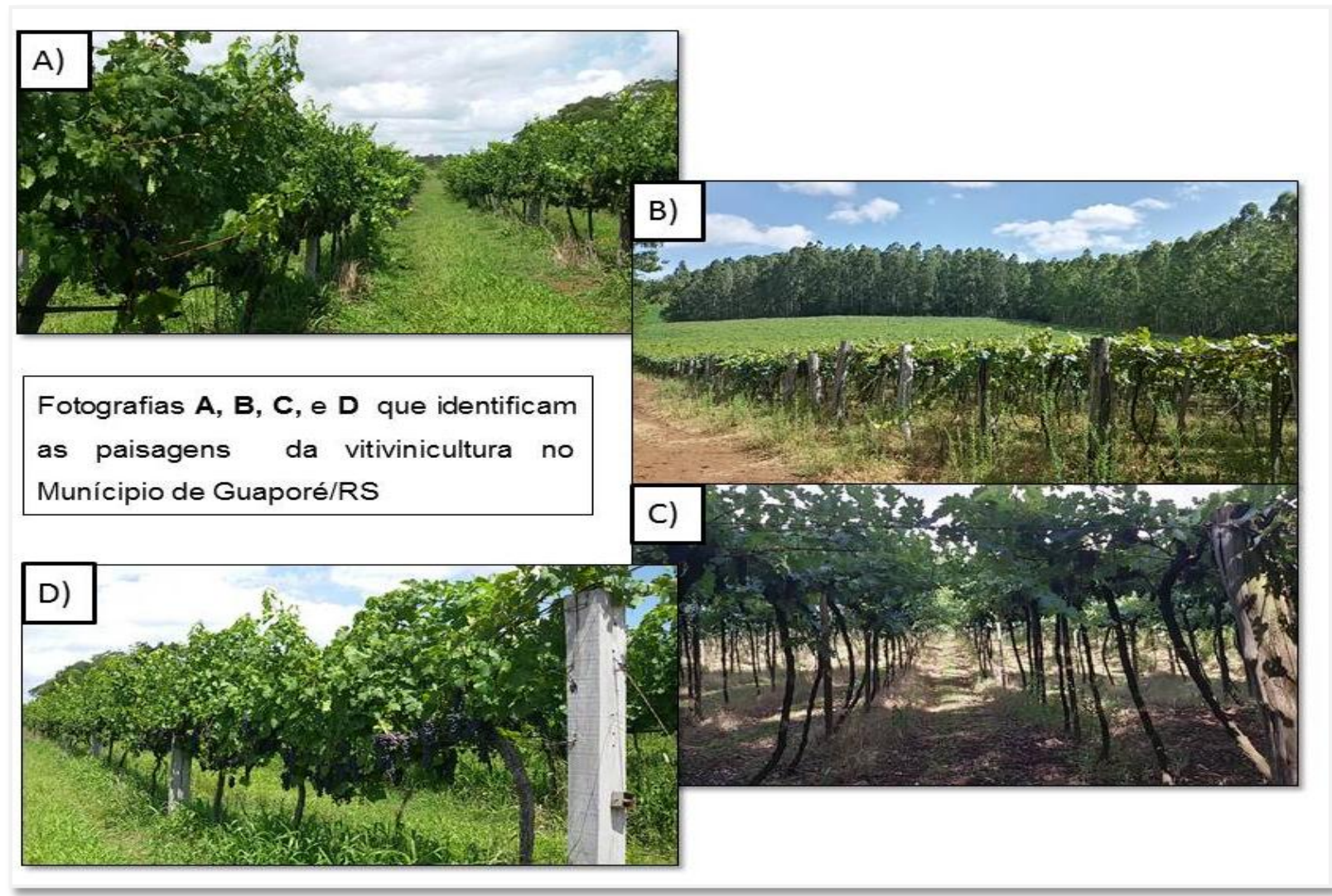

Fonte: Trabalho de campo, (Janeiro, 2017). Fotografia Mateus Pesseti.

Pode-se constatar, conforme o (Mosaico de fotos 1) que, as videiras são organizadas em fileiras, ocupando extensas áreas de relevo acidentado e com solo que favorecem sua produção. Cabe destacar que, o município de Guaporé perpetua-se entre os maiores produtores de uva da Microrregião em que está inserida. (IBGE, 2001, 2004, 2008, 2012 e 2016).

\section{Considerações finais}

O objetivo desta pesquisa estabeleceu-se na investigação das marcas da imigração italiana nas paisagens rurais de Guaporé/RS, especialmente no que se refere ao cenário produtivo agrícola. Tal análise foi possibilitada pelo levantamento de dados secundários do Sistemas de Recuperação Automática - SIDRA/IBGE (2001, 2004, 2008, 2012 e 2015) referente da produção agrícola, fundamentação teórica sobre os conceitos centrais da pesquisa, assim como, a realização do trabalho de campo.

Sendo assim, pode-se perceber que nas paisagens rurais do município de Guaporé, existe uma grande influência da imigração italiana. No que concerne o cenário produtivo agrícola, a presença do colono italiano dá-se no cultivo da milho e uva. A respeito do milho, as paisagens decorrentes da mesma ocupam grande parte da sua área rural. De tal produção, é 
gerada a farinha de trigo utilizada para o preparo de bolos e da polenta, tal como, servindo de alimento para a pecuária.

No que tange a produção da uva, a presença dos italianos se estabelece de maneira mais intensa. Desta forma, podemos inferir que a produção de uvas e vinhos caracteriza a presença da descendência italiana no município em análise. A uva é cultivada desde o surgimento da colônia que deu origem ao município de Guaporé, sendo destinada para a produção e comércio de vinhos e sucos.

Assim sendo, ao final desta pesquisa, constata-se que a unidade territorial analisada recebeu e ainda recebe grande influência da imigração italiana nas suas paisagens rurais. Destaca-se que, a influência de tal etnia vai além dos cenários produtivos e da arquitetura, ou seja, perpetuam-se outras marcas que extrapolam as paisagens rurais.

\section{Referências}

BECKER, Elsbeth Léia Spode. História do Pensamento Geográfico. 1. Ed. Santa Maria: Editora Centro Universitário Franciscano, 2006.

BERNARDES, Nilo. Bases Geográficas do Povoamento do Estado do Rio Grande do Sul. Ijuí: Ed. UNIJUÍ, 1997.

BEZZI, Lourdes Meri; MARAFON, Gláucio. Historiografia da Ciência Geográfica. Santa Maria: Editora UFSM, 2007.

BRUM NETO, Helena. Os territórios da imigração alemã e italiana no Rio Grande do Sul. Doutorado, Universidade Estadual Paulista Júlio de Mesquita Filho, 2012.

BRUM NETO, Helena. Os territórios da imigração italiana no Rio Grande do Sul. In: BRUM NETO, Helena; BEZZI, Meri Lourdes. Estudos de Geografia Cultural no Rio Grande do Sul . 1. Ed. Santa Maria: Editora Oikos. 2017. p. 11-36.

CAETANO, Jessica Neve; BEZZI, Lourdes Meri. Reflexões na Geografia Cultural: A materialidade e a imaterialidade da cultura. Revista Sociedade e Natureza, Uberlândia, ano 23 n. 3, 453-466, set/dez 2011.

CAVALCANTI, Augustinho Paulo Brito. Abordagens Geográficas no Estudo da Paisagem. Breves Contribuciones del Instituto de Estudios Geográficos, Tucuman, $n^{\circ} 22$ - Año, 2010/11, p. 57-74.

CLAVAL, Paul. Geografia Cultural. Florianópolis: Ed. Da UFSC, 2007.

CHRISTOFOLETTI, Antônio. Modelagem de sistemas ambientais. São Paulo: Editora Edgard Blucher Ltda, 1999 
COPATTI, Carina. Espaço Rural: Transformações, cultura e memória. Passo Fundo: Editora IMED, 2010

COSGROVE, D. - Em direção a uma Geografia Cultural Radical: Problemas da Teoria. In: CORREA R. L.; ROSENDAHL, Z. Introdução à Geografia Cultural. Rio de Janeiro, Bertrand Brasil, 2003.

CRUZ, Abigail Bruna da; ARAÚJO, Letícia Almeida; COSTA, Tamyris Maria Moreira da. Cultura rural: resistências e modificações observadas no campo a partir da inserção da tecnologia. ANAIS DO $2^{\circ}$ WORKSHOP DE GEOGRAFIA CULTURAL: Da cultura material ao simbolismo cultural 24 e 25 de junho de 2015 Alfenas-MG, p. 99-109.

CURTIS, Maria Luiza Lessa. Povoamento no Rio Grande do Sul. Revista Fundação de Economia e Estatística, 1963, p. 32-39.

DE BONI; Luis A.; COSTA, Rovílio. Os italianos do Rio Grande do Sul. 2. ed. Porto Alegre: EST; Caxias do Sul: Educs, Editora Vozes Ltda, 1982

FALCATE, Ivanira. As indicações geográficas e a reorganização do espaço rural brasileiro. In: MARAFON, Glaúcio José; RUA, João; RIBEIRO, Miguel Angelo. Abordagens teóricometodológicos em geografia agrária. Rio de Janeiro: Eduerj, 2007.

FURNALETTO, Beatriz Helena; KOZEL, Salete. Paisagem Cultural: Da cena visível a encenação da alma. Ateliê Geográfico - Goiânia, v. 8, n. 3, p.215-232, dez/2014.

INSTITUTO BRASILEIRO DE GEOGRAFIA E ESTATÍSTICA. Banco de dados, 2001, 2004, 2008, 2012, 2016. (Disponível em www.sidra.ibge.gov.br.).

PREFEITURA MUNICIPAL DE GUAPORÉ: disponível em: www.guapore.rs.gov.br. Acesso 2017.

SANTOS, Milton. Metamorfose do Espaço Habitado: Fundamento teórico e metodológicos da geografia. São Paulo: Hucitec, 1988.

SECRETARIA DE PLANEJAMENTO, GESTÃO E GOVERNAÇA: disponível em: www.atlassocioeconomico.rs.gov.br. Acesso 2017.

TROMBINI, Janaine; LAROQUE, Luís Fernando da Sil; ROSA, Cibele Caroline da. As práticas agrícolas dos descendentes de imigrantes açorianos e italianos na Região do Vale do Taquari/RS: aspectos relacionados ao desenvolvimento socioeconômico regional. Anais do VIII Seminário sobre Desenvolvimento Regional: Perspectivas e Desafios Santa Cruz do Sul, RS, Brasil, 13 a 15 de setembro de 2017.

VOIGT, Elizandra. Paisagem e Diversidade Cultural: As identidades culturais das distintas etnias em Santa Maria/RS. Mestrado em Geografia, Universidade Federal de Santa Maria, 2013.

WAGNER, Philip 1; MIKESELL, Marvin W. Os temas da Geografia Cultural. In: CORRÊA, Roberto Lobato; ROSENDAHL, Zeny. Introdução à Geografia Cultural. 6. ed. Rio de Janeiro: Editora Bertrand Brasil, 2014. 